\title{
Assessment of the level of anxiety and pain in women who do and do not attend childbirth classes during the SARS-CoV-2 pandemic
}

\section{Natalia Kuciel \\ Edyta Sutkowska (iD) \\ Karolina Biernat $(\mathbb{D}$ \\ Katarzyna Hap (D) \\ Justyna Mazurek (i) \\ Iwona Demczyszak (D)}

Department and Division of Medical Rehabilitation, Faculty of Medicine, Wroclaw Medical University, Wrocław, Poland
Correspondence: Natalia Kuciel Wroclaw Medical University, Borowska 213, Wrocław, 50-556, Poland Tel +48 660897427

Email natalia.kuciel@umed.wroc.pl
Introduction: Participation in childbirth classes is aimed at learning to cope with the anxiety that accompanies a woman during her pregnancy and childbirth. The aim of the study was to answer the question whether the lack of access to childbirth classes affected anxiety and perinatal pain in pregnant women who gave birth during the pandemic period.

Materials and Methods: This cross-sectional survey-based study involved women who were pregnant during the lockdown period. The respondents were asked to fill in the following questionnaires: a personal questionnaire, the Polish version of the Delivery Fear Scale and the Numeric Rating Scale for the assessment of average and maximum pain experienced during the labour. The survey was completed within 24-72 hours after the birth of the child. The obtained questionnaires were divided into 2 groups based on the information concerning attending or not attending childbirth classes (divided into subgroups): group A - patients participated in childbirth classes, and group B - patients did not participate in childbirth classes.

Results: Groups were homogeneous in terms of age, weight, height, body mass index and week of gestation. Perception of anxiety did not differ between groups. There was a correlation between particular formulation of the Delivery Fear Scale and "week of gestation" variable. In the group of women who gave birth naturally without anesthesia, there were no significant differences between groups in terms of mean and maximum pain during labour.

Conclusion: The level of anxiety and pain associated with childbirth is not modulated by childbirth classes during the pandemic period. There is s a correlation between particular formulation of the Delivery Fear Scale and "week of gestation" variable. In the group of women who gave birth naturally without anesthesia, there are no significant differences between groups in terms of mean and maximum pain during labour.

Keywords: delivery, education, women's health issue

\section{Introduction}

The impact of the SARS-CoV-2 pandemic on the functioning and accessibility of medical services for patients with medical conditions other than Covid-19 is not easy to assess. ${ }^{1,2}$ The current epidemiological situation has also affected women preparing for the birth of a child. Pregnant women are considered to be a high-risk population for contracting a viral infection and for the complications. ${ }^{3}$ Physiological changes occurring during the pregnancy generally increase the susceptibility to infections and may increase the risk of cardiovascular and respiratory 
complications. This may account for the more rapid progression of initial lesions to respiratory failure. ${ }^{4}$ However, there are no specific, separate recommendations for pregnant women in the current time of the pandemic. Like the general population, pregnant women are advised to limit direct contacts to a minimum. ${ }^{5}$ The current epidemic situation has forced a modification of the treatment of pregnant women. Follow-up visits of pregnant women conducted in person were minimized to basic pregnancy management regimen. A modification of the standard procedure for pregnant women has been introduced with respect to the use of childbirth classes, which have been part of pregnancy care for many years and whose role is to provide multifaceted assistance in preparing women for childbirth. Like rehabilitation centres, childbirth classes in Poland were closed during the lockdown period, which resulted in either complete abandonment of these activities by women or a search for new opportunities - provided by various online classes. Childbirth classes are among the proposals of the Ministry of Health concerning the organization of perinatal care and preparation for childbirth based on the document: Standards of Perinatal Care. ${ }^{6}$ Women in Poland can receive free antenatal education (financed from the budget) from the 21st week of their pregnancy. Based on these standards, a "Childbirth class" standard was developed in the Lower Silesia province. The standard details the course and the programme of group antenatal classes. ${ }^{7}$ In many countries around the world guidelines concerning the subject matter as well as the scope of education provided in group activities organized by such schools have also been developed. ${ }^{8,9}$ Participation in childbirth classes, which usually include theory and practice, is aimed at, among other things, learning to cope with the anxiety that accompanies a woman during her pregnancy and childbirth. ${ }^{10}$ According to studies, perinatal anxiety specifically increases with age (the later the pregnancy, the greater the anxiety), ${ }^{11}$ increased Body Mass Index (BMI), and week of delivery. ${ }^{12}$ Reduction of anxiety is achieved through education. Better understanding of the physiology of pregnancy and childbirth as well as creation of a network of support among parents-to-be participating in the classes reduces emotional tension. ${ }^{13}$ Reduced level of anxiety may also be related to a lower level of perinatal pain. Although anxiety in the final weeks preceding the labour is natural, the pandemic can add to the anxiety concerning health-related safety, the health of the baby, the conditions in which the birth will take place, the access to medical services during and after the labour and a general sense of uncertainty in response to dynamic events. Therefore, it seems all the more important that childbirth classes fulfil not only their educational but also their toning function with regard to pregnant women during the pandemic. However, since access to these forms of active, face-to-face education was significantly reduced by the lockdown, the question arises as to whether the lack of access to childbirth classes affected anxiety and perinatal pain in pregnant women who gave birth during the pandemic period.

\section{Materials and Methods}

This cross-sectional survey-based study involved women who were pregnant during the lockdown period which was introduced due to the coronavirus pandemic and gave birth between July 2020 and September 2020. The following inclusion criteria were applied: consent to participate in the study expressed by accepting the invitation to complete the survey (online or in person), completion of the survey within 24-72 hours after the birth of the child, uncomplicated pregnancy as well as delivery. Exclusion criteria: lack of consent to participate in the study, multiple pregnancy, pregnancy or/and delivery complications. All participants provided informed consent to take part in this study, in accordance with the Declaration of Helsinki. Surveys were obtained in two ways. The questionnaire was made available to the members of a perinatal group on Facebook, a closed group, or, alternatively, they could be completed in person at the Gynecology and Obstetrics Department at the hospital in Boleslawiec. In the case of the latter, the questionnaire was handed out upon respondent's acceptance by a midwife familiar with the contents of the study. In both cases, the content of the survey was the same. In the group of women who completed the online survey, the administrator of the group was first asked for a permission to post survey invitation in the above group. After his approval, the women who were interested in completing the survey were redirected to it. The respondents were asked to fill in the following questionnaires: a personal questionnaire, the Polish version of the Delivery Fear Scale (DFS) and the Numeric Rating Scale for the assessment of average and maximum pain experienced during the labour (NRS). The personal questionnaire included basic sociodemographic parameters such as: age, weight (on the day of delivery), height, BMI, number of deliveries, type of delivery, the week of pregnancy in which the delivery took place, single or multiple pregnancy as well as a question regarding the 
patient's participation in childbirth classes, including classes held online. The DFS questionnaire consisted of a numerical determination of the intensity of feelings during childbirth on a scale of $0-10$ (where 0 meant: "I completely disagree" and 10 meant: "I 100\% agree") (Suppl. 1). The scale has a good reliability: according to a study conducted by Wijma et al, Cronbach's alpha of the DRS was $0.88 .^{14}$ The level of anxiety in women was assessed 24-72 hours after delivery and was not assessed before giving birth, because the patients did not declare pre-delivery anxiety disorders.

The NRS consists of 11 levels assessing pain severity, from 0 to 10 , where 0 means no pain at all and 10 means the worst pain imaginable. The results of pain assessment were analysed only for the group of women who delivered naturally without anesthesia. The obtained questionnaires were divided into 2 groups based on the information concerning attending or not attending childbirth classes (divided into subgroups): group A - patients participated in childbirth classes, and group B - patients did not participate in childbirth classes. Group A included information from women who attended a childbirth classes in person, online, or in a combined manner. Group B included women who did not enroll in a childbirth classes. Only questionnaires completed by women who gave natural birth without anesthesia were taken into account for the assessment of perinatal pain. The questionnaires were described as A2 (attended childbirth classes and gave natural birth) and B2 (did not attend childbirth classes and gave natural birth), respectively. Additionally, correlations between the DFS score and the NRS as well as between the DFS score and selected variables, such as age at the time of delivery, BMI before pregnancy, or the week of delivery, were evaluated.

\section{Statistical Analyses}

The analysis was performed using the Statistica 12 package. Normality was verified with the use of the W Shapiro Wilk test. Student's $t$-test for independent variables or the Mann Whitney $U$-test were used to compare the groups. Relationships between qualitative variables were measured with the use of Pearson's Chi-square test. The non-parametric Kruskal-Wallis ANOVA test was used to compare 3 or more subgroups when the distribution of at least one variable deviated from normal. Correlation relationships between study variables, while maintaining non-normality of the distributions, were calculated using Spearman's rank correlation coefficient. Probability significance was set at $\mathrm{p}<0.05$.

\section{Ethical Approval}

The protocol of the study was approved by the Committee on Bioethics of Wroclaw Medical University no. KB-421/2020.

\section{Results}

A total of 75 questionnaires were obtained from women meeting the inclusion criteria. After a preliminary analysis, 3 surveys were rejected due to incomplete responses. Finally, 72 questionnaires were statistically analysed. The authors were unable to provide information on how many women in total found the information concerning the opportunity to complete the survey, but decided not to do it, or did not meet the inclusion criteria, due to the fact that part of the survey being completed on Facebook.

\section{Baseline Characteristics of the Study Groups}

There were 38 subjects in the group of women attending childbirth classes (group A1) and 34 subjects in the group of women not attending childbirth classes (group B1). There were no statistically significant differences between the groups in terms of age, weight, height, BMI of participants before delivery and the week of gestation in which the delivery took place (Table 1).

Twenty-one women in group A1 (55.3\%) and 22 women in group B1 (64.7\%) gave birth naturally without anesthesia ( $p=0.417$, Chi-square). In group A1, $5(13.2 \%)$ women gave birth naturally with anesthesia, while none of the women in group B1 received anesthesia during the labour ( $p=0.028$, Chi-square). Twelve women in group A1 (35.4\%) and 12 women in group B1 (31.6\%) delivered by caesarean section ( $\mathrm{p}=0.370$, Chi-square).

The groups differed in terms of the number of multiparas women: there were 14 multiparas women in group A1 (36. $8 \%)$ and 22 in group B1 (64. 7\%) $(\mathrm{p}=0.018)$ (Figure 1).

\section{Evaluation of the Level of Anxiety in the Groups and Its Correlation with Selected Variables}

Perception of anxiety did not differ between the groups. Results relating to each expression assessed in the DFS are presented in Table 2. 
Table I Characteristics of the Study Groups

\begin{tabular}{|c|c|c|c|c|c|c|c|}
\hline \multirow{2}{*}{ Parameter } & \multicolumn{3}{|c|}{ AI $(n=38)$} & \multicolumn{3}{|c|}{ BI $(n=34)$} & \multirow[t]{2}{*}{$\mathbf{p}$} \\
\hline & Mean & Median & SD & Mean & Median & SD & \\
\hline Age (years, months) & 30.4 & 30.5 & 5.0 & 30.3 & 30.5 & 5.0 & $0.991 *$ \\
\hline Body weight at the time of birth $(\mathrm{kg})$ & 77.0 & 75.5 & 12.4 & 77.2 & 76.0 & 12.2 & $0.938 *$ \\
\hline Height $(\mathrm{cm})$ & 166.5 & 165.0 & 6.0 & 164.6 & 165.0 & 6.2 & $0.502 * *$ \\
\hline BMI At the time of birth $\left(\mathrm{kg} / \mathrm{m}^{2}\right)$ & 27.8 & 27.1 & 4.1 & 28.7 & 28.9 & 5.5 & $0.088^{*}$ \\
\hline Week of gestation & 39.8 & 40.0 & I.I & 39.5 & 39.0 & I.I & $0.169 * *$ \\
\hline
\end{tabular}

Notes: AI - group of women who attended childbirth classes; BI - group of women who did not attend childbirth classes *Student's $t$-test for independent variables; **Nonparametric Mann Whitney U-test.

The evaluation of the correlation between anxiety and age revealed no statistical significance (Table 3). For the correlation between the anxiety level and the BMI value, a statistically significant correlation was revealed for one formulation (Table 3); the correlation had a negative direction. In the case of the remaining statements of the DFS, no significance was demonstrated when assessing their correlation with the BMI value. Most associations were observed between particular formulations of the scale and the "week of gestation" variable. Statistical significance of such correlations was demonstrated for as many as 5 formulations, with simultaneously different direction of correlation (Table 3).

\section{Assessment of Pain Levels in a Group of Women Who Gave Birth Naturally without Anesthesia, and Its Correlation with the Perceived Anxiety}

The assessment of labour pain concerned only patients who gave birth naturally and without anesthesia. Both subgroups: A2 $(n=21)$ and B2 $(n=22)$ were homogeneous in terms of height ( $\mathrm{p}=0.632$, Student's $t$-test), weight ( $\mathrm{p}=0.853$, Student's $t$-test), BMI (0.964, Student's $t$-test), age ( $\mathrm{p}=0.782$, Student's $t$-test) and the week of gestation in which the delivery took place ( $\mathrm{p}=0.896$, Student's $t$-test). There were no significant

\section{$p=0.018$}

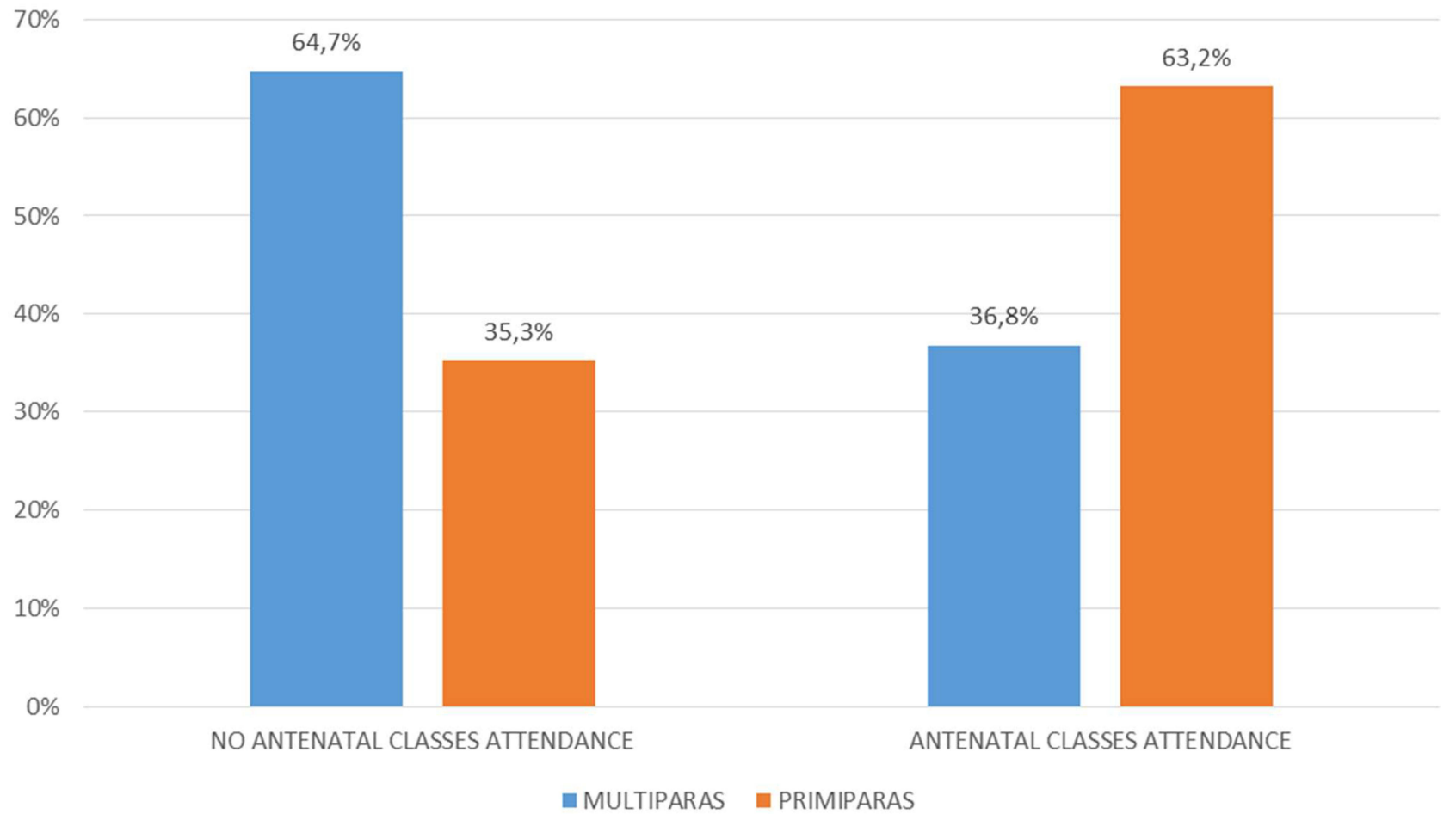

Figure I Percentage of women who attended childbirth classes during the lockdown caused by the SARS-cov-2 pandemic, by multiple births and primiparas. 
Table 2 Evaluation of Anxiety Level According to Delivery Fear Scale in Groups AI and BI

\begin{tabular}{|c|c|c|c|c|c|c|c|}
\hline \multirow{2}{*}{ Phrase* $\quad$ Group } & \multicolumn{3}{|c|}{ AI $(n=38)$} & \multicolumn{3}{|c|}{ B I $(n=34)$} & \multirow[t]{2}{*}{$\mathbf{P}^{*}$} \\
\hline & Mean & Median & SD & Mean & Median & SD & \\
\hline I can stand the pain & 7.7 & 8.0 & 2.9 & 6.6 & 8.0 & 3.6 & 0.361 \\
\hline I feel very helpless & 5. & 5.0 & 3.4 & 5.3 & 5.5 & 3.7 & 0.710 \\
\hline This feels positive & 6.9 & 8.0 & 2.8 & 6.3 & 7.5 & 3.8 & 0.761 \\
\hline This feels as if I will never be able to get out of here & 5.8 & 6.5 & 3.8 & 5.1 & 5.5 & 3.8 & 0.315 \\
\hline I can manage this & 7.5 & 9.0 & 2.9 & 6.6 & 7.0 & 3.3 & 0.213 \\
\hline I do not want to go on any more & 4.7 & 4.0 & 3.7 & 4.1 & 3.5 & 3.6 & 0.558 \\
\hline In the midst of all this I feel happy & 5.6 & 5.5 & 3.4 & 5.1 & 5.0 & 3.6 & 0.548 \\
\hline I feel as if I will give up soon & 4.1 & 3.0 & 3.4 & 4.2 & 2.5 & 3.8 & 0.822 \\
\hline This is taking forever & 5.4 & 5.5 & 4.0 & 4.8 & 5.0 & 3.8 & 0.417 \\
\hline I feel calm & 5.2 & 5.0 & 3.1 & 4.6 & 5.0 & 3.4 & 0.378 \\
\hline
\end{tabular}

Notes: AI - group of women who attended childbirth classes; BI - group of women who did not attend childbirth classes, $\mathrm{p}$ - non-parametric Mann Whitney U-test. *Delivery Fear Scale phrases reprinted by permission of the publisher (Taylor \& Francis Ltd, http://tandfonline.com) from: Wijma K, Alehagen S, Wijma B. Development of the Delivery Fear Scale. Journal of Psychosomatic Obstetrics \& Gynecology. 2002;23(2):97-107. Copyright 2002 Taylor \& Francis. Published online 07 Jul $2009 .^{14}$

Table 3 Level of Correlation Between Anxiety Expressed by the Delivery Fear Scale and Selected Sociodemographic Factors

\begin{tabular}{|l|l|l|l|}
\hline \multicolumn{1}{|c|}{ Variable N=72 } & Age & BMI at Birth & Week of Gestation \\
\hline I can stand the pain & $0.123(p=0.304)$ & $0.090(p=0.450)$ & $0.436(p=0.255)$ \\
I feel very helpless & $0.006(p=0.960)$ & $-0.187(p=0.116)$ & $0.106(p=0.377)$ \\
This feels positive & $-0.059(p=0.621)$ & $0.06 \mid(p=0.612)$ & $-0.108(p=0.365)$ \\
This feels as if I will never be able to get out of here & $-0.215(p=0.069)$ & $-0.340(p=0.003)$ & $0.238(p=0.044)$ \\
I can manage this & $-0.065(p=0.615)$ & $-0.038(p=0.750)$ & $-0.164(p=0.167)$ \\
I do not want to go on any more & $-0.092(p=0.444)$ & $-0.187(p=0.115)$ & $0.288(p=0.014)$ \\
In the midst of all this I feel happy & $-0.125(p=0.297)$ & $0.027(p=0.833)$ & $-0.235(p=0.047)$ \\
I feel as if I will give up soon & $0.032(p=0.788)$ & $-0.069(p=0.563)$ & $0.328(p=0.005)$ \\
This is taking forever & $-0.059(p=0.623)$ & $-0.148(p=0.214)$ & $0.222(p=0.061)$ \\
I feel calm & $-0.090(p=0.454)$ & $0.013(p=0.917)$ & $-0.265(p=0.025)$ \\
\hline
\end{tabular}

Notes: *Delivery Fear Scale phrases reprinted by permission of the publisher (Taylor \& Francis Ltd, http://tandfonline.com) from: Wijma K, Alehagen S, Wijma B. Development of the Delivery Fear Scale. Journal of Psychosomatic Obstetrics \& Gynecology. 2002;23(2):97-107. Copyright 2002 Taylor \& Francis. Published online 07 Jul 2009..$^{14}$

Abbreviations: $\mathrm{N}$, number of participants; BMI, body mass index.

differences between the subgroups in terms of the mean and maximum pain scores during the labour (Table 4).

Directions of correlations varied for different relationships (Table 5).

\section{Discussion}

Scientific evidence concerning the effectiveness of childbirth classes indicates that knowledge about pregnancy, childbirth and parenting increases after attending classes at such classes. However, there is little scientific evidence to support the impact of attending childbirth classes on childbirth. This study attempts to assess the impact of attending childbirth classes on anxiety and pain in perinatal women. The objectives of the study were evaluated with the use of commonly available scales assessing anxiety and pain. It should be noted that other potential benefits of education provided by the programme of childbirth classes were not the focus of our evaluation. During natural labour, pain is associated with contractions, while in the case of a cesarean section it occurs after the effects of anesthesia administered before the surgery have subsided. Anxiety affects $5-26 \%$ of pregnant women and in the most severe cases it manifests as tokophobia. ${ }^{15}$ Anxiety may cause negative perception of childbirth and reduce natural satisfaction of childbirth, thus predisposing a woman to postpartum depression and posttraumatic stress disorder. ${ }^{16}$ Epidural, which is often offered to women, may modulate anxiety, pain and physical exhaustion, impacting their 
Table 4 Pain Level in Women Giving Birth Naturally without Anesthesia in Both Groups

\begin{tabular}{|l|l|l|l|l|l|l|l|}
\hline \multirow{2}{*}{ Pain Intensity } & \multicolumn{3}{|c|}{ Group A2 (n=21) } & \multicolumn{3}{c|}{ Group B2 (n=22) } \\
\cline { 2 - 8 } & Mean & Mediana & SD & Mean & Mediana & SD \\
\hline Mean pain & 6.9 & 7.0 & 2.0 & 7.3 & 7.0 & 2.0 & 0.512 \\
Maximum pain & 9.2 & 10.0 & 1.0 & 9.4 & 10.0 & 1.0 & 0.610 \\
\hline
\end{tabular}

Notes: A2 - a group of women who gave birth naturally without anaesthesia and attended childbirth classes; BI - a group of women who gave birth naturally without anaesthesia and did not attend childbirth classes, $\mathrm{P}$ - Student's $t$-test for independent variables.

Table 5 Relationship Between the Level of Anxiety and the Perception of Average and Maximum Pain in the Group of Women Who Gave Birth Naturally without Anaesthesia

\begin{tabular}{|l|l|l|l|l|}
\hline \multirow{2}{*}{ Phrase* } & \multicolumn{2}{c|}{ Mean Pain } & \multicolumn{2}{c|}{ Maximum Pain } \\
\cline { 2 - 5 } & $\mathbf{R}$ & $\mathbf{P}$ & $\mathbf{R}$ & $\mathbf{P}$ \\
\hline I can stand the pain & -0.388 & 0.010 & $-0.26 \mathrm{I}$ & 0.09 I \\
I feel very helpless & 0.434 & 0.004 & 0.307 & 0.045 \\
This feels positive & -0.459 & 0.002 & $-0.36 \mathrm{I}$ & 0.017 \\
This feels as if I will never be able to get out of here & 0.415 & 0.006 & 0.576 & 0.000 \\
I can manage this & $-0.41 \mathrm{I}$ & 0.006 & -0.377 & 0.013 \\
I do not want to go on any more & 0.374 & 0.013 & 0.385 & 0.01 I \\
In the midst of all this I feel happy & -0.276 & 0.073 & -0.442 & 0.003 \\
I feel as if I will give up soon & 0.244 & 0.115 & 0.424 & 0.005 \\
This is taking forever & 0.237 & 0.126 & 0.340 & 0.026 \\
I feel calm & -0.183 & 0.239 & -0.435 & 0.004 \\
\hline
\end{tabular}

Notes: *Delivery Fear Scale phrases reprinted by permission of the publisher (Taylor \& Francis Ltd, http://tandfonline.com) from: Wijma K, Alehagen S, Wijma B. Development of the Delivery Fear Scale. Journal of Psychosomatic Obstetrics \& Gynecology. 2002;23(2):97-107. Copyright 2002 Taylor \& Francis. Published online 07 Jul 2009. ${ }^{14}$

cooperation during natural deliveries. ${ }^{17}$ Information on the methods of reducing labour pain is provided to women in the following ways during childbirth classes. Many women opt for anesthesia during labor to minimize pain and increase comfort during the delivery. The relationship between anxiety and pain is bidirectional. ${ }^{18}$ Based on research, we know that anxiety levels during childbirth are affected by, among other things, high (higher than expected) level of pain; on the other hand, the initial level of anxiety affects the experience of labour pain and may be a factor significantly hindering labour. ${ }^{17,19}$ Studies show that anxiety experienced during the labour may be of high intensity, irrespective of whether a woman has received anesthesia or not. ${ }^{16}$ In addition, the use of epidural analgesia during childbirth provides no measurable benefits in terms of reducing the experience of anxiety during childbirth, despite reducing the pain. ${ }^{19}$ Studies available in the literature show that women who choose anesthesia may experience higher levels of anxiety than those who give birth without it which may significantly contribute to prolonged labor. ${ }^{20}$ Adams et al assessed the relationship between the occurrence of childbirth anxiety and its impact on the length of labour. The study proves that labour is longer in women who reported experiencing anxiety before childbirth compared to women who did not report anxiety. ${ }^{21}$

The method of delivery (natural delivery vs caesarean section) and the moment of making decision in this regard (emergency vs elective caesarean section) may contribute to an increased level of anxiety. While emergency surgical delivery has been shown to increase stress and anxiety related to childbirth, ${ }^{22}$ elective caesarean section has not been shown to significantly reduce anxiety. ${ }^{23}$ Therefore, even though the mode in which this procedure was performed was not analyzed in our study, it does not appear (based on the scarce literature available) to significantly affect the obtained results. This knowledge needs to be broadened and verified in further research.

The aim of our study was to assess differences in the level of anxiety and labour pain in an extremely special period, ie the first part of the pregnancy, during of the SARS-Cov-2 pandemic, in women who had the opportunity to prepare for 
childbirth and motherhood at childbirth classes and those who did not have such opportunity. By significantly limiting access to these classes, the lockdown imposed during the pandemic incidentally provided an opportunity to assess whether education provided during such classes, which should positively modulate both mentioned variables, actually fulfils its function. Without the epidemiological restrictions imposed by the government, it would be extremely difficult to obtain consent for such an experiment, due to the widespread promotion of education in childbirth classes and the fact that they are financed from the state budget.

The results obtained in our study revealed that the education received in childbirth classes did not have an impact on the level of anxiety and pain. The obtained results also made it possible to analyse the relationship between these variables as well as between them and other selected parameters. Given that the state of pandemic itself causes elevated levels of anxiety among people, ${ }^{24}$ the tonic effect of the education provided in childbirth classes should be particularly strong during this period. Ayaz et al demonstrated that there was a strong need for education and comprehensive support for pregnant women during the lockdown to prevent future psychological trauma after birth. ${ }^{24}$ The specificity of the state of pandemic and its negative impact on women's psychology were confirmed in the study conducted by Parra-Saavedra et $\mathrm{al}^{25}$ In Poland, a prepandemic evaluation similar to our study was performed by Kacperczyk-Bartnik et al who obtained results similar to ours. ${ }^{26}$ In their study, birthing school attendance had no impact on pain level in all of the tested patients. In the multiparas group of women birthing school did not significantly decreased anxiety level during delivery. This brings into question the potential benefits, which can be gained by women in the aforementioned educational process with regard to variables as important as the sense of anxiety and pain. To a large extent, childbirth classes are funded from the state budget; therefore, it seems that a clear assessment of the legitimacy of maintaining these classes in their present form, based on an analysis of a sufficiently large number of patients, is needed.

One of the limitations of our study is certainly the lack of differentiation of the results obtained for primiparas and multiparas. Due to the total number of analysed questionnaires, it could not be performed. In addition, other elements that may be impacted by the education received at childbirth classes, which were not assessed in our study, should be evaluated in terms of their modulability. It stems from the fact that the effects of such education in the group of primiparas and multiparas may differ. $^{11,19}$ The impact of the number of births on the analysed variables may not be so clear-cut. The first pregnancy and delivery may be associated with an increased level of anxiety about a new, unknown situation; ${ }^{22}$ on the other hand, bad experiences from previous deliveries may increase the level of anxiety in multiparas women. ${ }^{11,19,21}$ It also seems that an evaluation of the effects obtained by women participating in typical childbirth classes and women participating in online classes should enable a more precise reference to the effectiveness of these activities.

This element of the analysis in relation to our work, we can only suggest that there is a need to assess whether childbirth classes can provide measurable benefits in terms of reducing anxiety and pain in pregnant women when they are preparing for childbirth for the first time, as the groups in our study were not homogeneous in this regard.

It also seems that an evaluation of the effects obtained by women participating in a typical childbirth classes and women participating in online classes should enable a more precise reference to the effectiveness of these activities.

The additional assessment of the correlation between anxiety and pain confirmed that the higher the number of positive expressions on the DFS scale, the lower the sensation of pain; however, it was not affected by attending childbirth classes. Similarly, negative expressions confirming higher levels of anxiety in women correlated positively with pain levels. In addition, it was shown that the level of anxiety was influenced by the stage of pregnancy at the time of delivery, which is consistent with the previous observations of other authors. ${ }^{27-29}$

The signals from smaller observations seem to indicate that there is a need for a large study, which would clarify whether childbirth classes could have an impact on elements of perinatal care and which elements it would be. It may be helpful to create a more precise curriculum and make better use of the time allocated for education during childbirth classes so that they could prepare women for childbirth by facilitating its course and supporting mothers in the postpartum period.

\section{Conclusions}

-The level of anxiety associated with childbirth and the level of pain during childbirth is not modulated by childbirth classes during the pandemic period.

-There is s a correlation between particular formulation of the Delivery Fear Scale and "week of gestation" variable.

-In the group of women who gave birth naturally without anesthesia, there are no significant differences 
between groups in terms of mean and maximum pain during labour.

\section{Future Directions}

Considering the obtained results and the reports of other authors, it seems necessary to conduct a multi-centre study on an appropriately large group of women to determine the need for childbirth classes or to identify the group of women to whom participation in such classes brings the greatest benefits. In further studies, it would seem advisable to distinguish between primiparas and multiparas, and to analyze differences between the effects, depending on the type of participation (online vs standard) in childbirth classes.

\section{Acknowledgments}

We would like to thank the director of Zespół Opieki Zdrowotnej $\mathrm{w}$ Bolesławcu for the permission to conduct research on the gynecological department and midwife Paulina Wiśniowska, who collected surveys among pregnant women.

\section{Funding}

Wroclaw Medical University; SUB.C310.21.059.

\section{Disclosure}

All authors reported no conflicts of interest for this work.

\section{References}

1. Cesari M, Proietti M. Editorial: geriatric medicine in Italy in the time of COVID-19. J Nutr Health Aging. 2020;24:459-460. doi:10.1007/ s12603-020-1354-z

2. Monaghesh E, Hajizadeh A. The role of telehealth during COVID-19 outbreak: a systematic review based on current evidence. BMC Public Health. 2020;20:1193. doi:10.1186/s12889-020-09301-4

3. Stockman LJ, Lowther SA, Coy K, Saw J, Parashar UD. SARS during pregnancy, United States. Emerg Infect Dis. 2004;10:1689-1690. doi:10.3201/eid1009.040244

4. Ravaldi C, Wilson A, Ricca V, Homer C, Vannacci A. Pregnant women voice their concerns and birth expectations during the COVID-19 pandemic in Italy. Women Birth. 2020;S1871-S5192 (20):30280-30288.

5. Overbeck G, Graungaard AH, Rasmussen IS, et al. Pregnant women's concerns and antenatal care during COVID-19 lock-down of the Danish society. Dan Med J. 2020;67:A06200449.

6. Internetowy System Aktów Prawnych. Rozporządzenie Ministra Zdrowia z dnia 16 sierpnia 2018r. 6. w sprawie standardu organizacyjnego opieki okołoporodowej. Dz.U.2018 poz.1756 [Regulation of the Minister of Health of August 16, 2018. 6. on the organizational standard of perinatal care. Journal of Laws 2018, item 1756]. Available from: isap.sejm.gov.pl/isap.nsf/DocDetails.xsp?id=WDU20180001756. Polish.

7. Standard edukacja przedporodowa "Szkoła Rodzenia" [Standard antenatal education "Birth School"]; 2021. Available from: https://www.duw. pl/pl/urzad/zdrowie-publiczne/matka-i-dziecko/104,Szkoly-Rodzenia. html?search=8131713395. Accessed July 17, 2021. Polish.
8. NHS. Antenatal classes; 2018.Available from: https://www.nhs.uk/ pregnancy/labour-and-birth/preparing-for-the-birth/antenatal-classes/. Accessed January 31, 2018.

9. Recommendations for antenatal education content, development and delivery; 2018. Available from: https://clinicalexcellence.qld.gov.au/ sites/default/files/docs/priority-area/service-improvement/maternityservice-improvement/recommendations-antenatal-education.pdf. Accessed July 17, 2021.

10. Krysa J, Iwanowicz-Palus GJ, Bień AM, Rzońca E, Zarajczyk M. Antenatal classes as a form of preparation for parenthood: analysis of benefits of participating in prenatal education. Pol J Public Health. 2016;126:192-196. doi:10.1515/pjph-2016-0040

11. Rouhe H, Salmela-Aro K, Halmesmäki E, Saisto T. Fear of childbirth according to parity, gestational age, and obstetric history. BJOG. 2009;116:67-73. doi:10.1111/j.1471-0528.2008.02002.x

12. Sydsjö G, Bladh M, Lilliecreutz C, Persson A-M, Vyöni H, Josefsson A. Obstetric outcomes for nulliparous women who received routine individualized treatment for severe fear of childbirth - a retrospective case control study. BMC Pregnancy Childbirth. 2014;14:126. doi:10.1186/1471-2393-14-126

13. Nolan M. Educators' experience of facilitating antenatal education online. Int J Birth Parent Educ. 2021; Epub. Available from: https:// ijbpe.com/10-front-page-news/506-educators'-experience-of-facilitat ing-antenatal-education-online

14. Wijma K, Alehagen S, Wijma B. Development of the delivery fear scale. J Psychosom Obstet Gynaecol. 2002;23(2):97-107. [PMID: 12189903]. doi:10.3109/01674820209042791

15. Fenwick J, Gamble J, Nathan E, Bayes S, Hauck Y. Pre- and postpartum levels of childbirth fear and the relationship to birth outcomes in a cohort of Australian women. J Clin Nurs. 2009;18:667e77. doi:10.1111/j.1365-2702.2008.02568.x

16. Gosselin P, Chabot K, Beland M, Goulet-Gervais L, Morin AJ. Fear of childbirth among nulliparous women: relations with pain during delivery, post-traumatic stress symptoms, and postpartum depressive symptoms. Encephale. 2016;42:191-196. doi:10.1016/j.encep.2016.01.007

17. Brownridge P. The nature and consequences of childbirth pain. Eur J Obstet Gynecol Reprod Biol. 1995;59(Suppl):S9-S15. doi:10.1016/ 0028-2243(95)02058-Z

18. Alehagen S, Wijma K, Wijma B. Fear during labor. Acta Obstet Gynecol Scand. 2001;80(4):315-320. doi:10.1034/j.16000412.2001.080004315.x

19. Gökçe Isbir G, Inci F, Önal H, Dıkmen Yıldız P. The effects of antenatal education on fear of childbirth, maternal self-efficacy and post-traumatic stress disorder (PTSD) symptoms following childbirth: an experimental study. Appl Nurs Res. 2016;32:227-232. doi:10.1016/j.apnr.2016.07.013

20. Maimburg RD, Vaeth M, Dürr J, Hvidman L, Olsen J. Randomised trial of structured antenatal training sessions to improve the birth proces. BJOG. 2010;117(8):921-928. doi:10.1111/j.1471-0528.2010.02584.x

21. Adams SS, Eberhard-Gran E, Eskild A. Fear of childbirth and duration of labour: a study of 2206 women with intended vaginal delivery. BJOG.2012;119(10):1238-1246. doi:10.1111/j.1471-0528.2012.03433.x.

22. Olieman RM, Siemonsma F, Bartens MA, Garthus-Niegel S, Scheele F, Honig A. The effect of an elective cesarean section on maternal request on peripartum anxiety and depression in women with childbirth fear: a systematic review. BMC Pregnancy Childbirth. 2017;17(1):195. doi:10.1186/s12884-017-1371-z

23. Salari N, Hosseinian-Far A, Jalali R, et al. Prevalence of stress, anxiety, depression among the general population during the COVID-19 pandemic: a systematic review and meta-analysis. Global Health. 2020;16:57. doi:10.1186/s12992-020-00589-w

24. Ayaz R, Hocaoğlu M, Günay T, Yardımcı OD, Turgut A, Karateke A. Anxiety and depression symptoms in the same pregnant women before and during the COVID-19 pandemic. $J$ Perinat Med. 2020;48(9):965-970. doi:10.1515/jpm-2020-0380 
25. Parra-Saavedra M, Villa-Villa I, Pérez-Olivo J, et al. Attitudes and collateral psychological effects of COVID-19 in pregnant women in Colombia. Int J Gynecol Obstet. 2020;151:1-6.

26. Kacperczyk-Bartnik A, Bartnik P, Symonides A, Sroka-Ostrowska N, Dobrowolska-Redo A, Romejko-Wolniewicz E. Association between antenatal classes attendance and perceived fear and pain during labour. Taiwan J Obstet Gynecol. 2019;58(4):492-496. doi:10.1016/ j.tjog.2019.05.011
27. Lizis E, Mokrzycka K, Jandziś S. Wpływ edukacji przedporodowej na przebieg ciąży, porodu i wczesne macierzyństwo. Med Og Nauk $Z d r .2016 ; 22(4): 264-269$.

28. Saisto T, Ylikorkala O, Halmesmäki E. Factors associated with fear of delivery in second pregnancies. Obstet Gynecol. 1999;94(5):679-682.

29. Zar M, Wijma K, Wijma B. Pre-and postpartum fear of childbirth in nulliparous and parous women. Scand J Behav Ther. 2001;30:75-84. doi:10.1080/02845710121310

\section{Publish your work in this journal}

Risk Management and Healthcare Policy is an international, peerreviewed, open access journal focusing on all aspects of public health, policy, and preventative measures to promote good health and improve morbidity and mortality in the population. The journa welcomes submitted papers covering original research, basic science, clinical \& epidemiological studies, reviews and evaluations, guidelines, expert opinion and commentary, case reports and extended reports. The manuscript management system is completely online and includes a very quick and fair peer-review system, which is all easy to use. Visit http://www.dovepress.com/testimonials.php to read real quotes from published authors.

Submit your manuscript here: https://www.dovepress.com/risk-management-and-healthcare-policy-journal 